\title{
Motor function measure scale, steroid therapy and patients with Duchenne muscular dystrophy
}

\author{
Medida de função motora, corticoterapia e pacientes com distrofia muscular de Duchenne \\ Elaine C. da Silva', Darlene L. Machado', Maria B. D. Resende¹, Renata F. Silva', Edmar Zanoteli², \\ Umbertina C. Reed ${ }^{1}$
}

\begin{abstract}
Objective: To assess the evolution of motor function in patients with Duchenne muscular dystrophy (DMD) treated with steroids (prednisolone or deflazacort) through the Motor Function Measure (MFM), which evaluates three dimensions of motor performance (D1, D2, D3). Methods: Thirty-three patients with DMD (22 ambulant, 6 non-ambulant and 5 who lost the capacity to walk during the period of the study) were assessed using the MFM scale six times over a period of 18 months. Results: All the motor functions remained stable for 14 months in all patients, except D1 for those who lost their walking ability. In ambulant patients, D2 (axial and proximal motor capacities) motor functions improved during six months; an improvement in D3 (distal motor capacity) was noted during the total follow-up. D1 (standing posture and transfers) and total score were useful to predict the loss of the ability to walk. Conclusions: The use of the MFM in DMD patients confirms the benefits of the steroid treatment for slowing the progression of the disease.
\end{abstract}

Key words: motor function measure, muscular dystrophy, Duchenne, neuromuscular disease.

\section{RESUMO}

Objetivo: Avaliar a evolução da função motora de pacientes com distrofia muscular de Duchenne (DMD) em corticoterapia (predinisolona e deflazacort), por meio da escala Medida da Função Motora (MFM), que avalia três dimensões de funções motoras (D1, D2, D3). Métodos: Trinta e três pacientes com DMD (22 deambulantes, seis cadeirantes e cinco que perderam a capacidade de andar ao longo do estudo) foram avaliados pela escala MFM em seis momentos durante 18 meses. Resultados: Todas as funções motoras mantiveram-se estáveis durante 14 meses, exceto D1 para os pacientes que perderam a marcha. Nos pacientes deambulantes, a D2 (função motora axial e proximal) apresentou melhora durante seis meses. Melhora em D3 (função motora distal) também foi observada durante o seguimento. A D1 (postura em pé e transferências) e o escore total foram importantes para predizer a perda de marcha. Conclusões: O uso da MFM nos pacientes com DMD confirma os benefícios do tratamento com corticoides na diminuição da velocidade de progressão da doença.

Palavras-Chave: medida da função motora, distrofia muscular de Duchenne, doença neuromuscular.

Duchenne muscular dystrophy (DMD) is the most common and severe muscular dystrophy, affecting about 1:3500 live male births ${ }^{1}$ and causing loss of the ability to walk independently by 10 to 12 years of age. Its treatment remains palliative and relies mainly on steroids and physiotherapy, both in order to slow the loss of motor function ${ }^{2-4}$. Several tests have been reported in the literature to assess muscle strength and functional ability, to monitor the progression of the disease, and to evaluate the results of drug interventions and rehabilitation $^{4-12}$. However, most instruments involve ambulant patients, making adjustments and/or additional assessments necessary when the disease progresses ${ }^{8,9}$. The Motor Function Measure (MFM), which was an assessment tool to measure motor function in patients with neuromuscular disorders, was developed $^{13}$ in 2005, in France, and it was later validated in Brazil ${ }^{14}$. It includes 32 items that evaluate three dimensions of motor performance, including specific motor functions, such as transfers and standing posture (D1), proximal and axial (D2), distal (D3) and a total MFM score involving all of the motor dimensions. The items are scored and summed to comprise a total score, in which the maximum represents normal motor function.

\footnotetext{
1 Department of Neurology, Medical School of the University of São Paulo, São Paulo SP, Brazil;

${ }^{2}$ Neuromuscular Section, Associação de Assistência à Criança Deficiente, São Paulo SP, Brazil.

Correspondence:Umbertina C Reed; Avenida Doutor Enéas de Carvalho Aguiar 255 / sala 5.131;05403-900 São Paulo SP - Brasil; E-mail: ucontireed@hcnet.usp.br / elainne_cris@yahoo.com.br

Conflict of interest: There is no conflict of interest to declare.

Received 19 July 2011; Received in final form 30 October 2011; Accepted 07 November 2011
} 
Using this tool, longitudinal studies to assess motor function are possible in both ambulant and wheelchair patients. The purpose of this study was to verify the evolution of motor function with this new assessment tool in patients with DMD, who were on steroid therapy.

\section{METHODS}

The study included 44 patients (ambulant and non-ambulant) with DMD, aged six to 16 years-old. The DMD diagnosis was confirmed by molecular analysis and/or immunohistochemistry and Western blot for dystrophin in muscle biopsy, and all patients were submitted to laboratory tests before the onset of steroid therapy utilizing two possible schemes: prednisolone $(0.75 \mathrm{mg} / \mathrm{kg}$ per day intermittently ten days on and ten days off) for those children less than seven years-old, or deflazacort (0.9 mg/kg/day) daily for the older ones.

All patients were able to actively collaborate in the motor tasks of the MFM. An initial assessment was made to collect general information, including the date of loss of ambulation and the type and weekly frequency of attendance at physical therapy center. When patients did not attend any type of physical therapy (hydrotherapy and conventional physical therapy), they were counseled and referred to specialized rehabilitation care centers. As those treatments were not carried out at the same rehabilitation center, all caregivers were explained about how doing some traditionally physical exercises at home. After having obtained the authors' authorization, we applied the MFM and registered the aspects of motor function (D1, D2, D3) and the total MFM score, according

Table 1. General data of 33 steroid-treated patients with Duchenne muscular dystrophy.

\begin{tabular}{lcc}
\multicolumn{1}{c}{ Patients } & $\begin{array}{c}\text { Age (mean/minimum- } \\
\text { maximum) }\end{array}$ & $\begin{array}{c}\text { Age at loss of } \\
\text { walking capacity }\end{array}$ \\
\hline Ambulant & $7.6(6-10)$ & - \\
$n=22(66.7 \%)$ & \pm 1.2 & $10.4(9-12)$ \\
Loss of walking & $10(9-11)$ & \pm 1.1 \\
capacity & \pm 0.7 & \\
$n=5(15.1 \%)$ & & - \\
Non-ambulant & $12.5(8-16)$ & \\
$n=6(18.2 \%)$ & \pm 3.1 & \\
\hline
\end{tabular}

to materials and methods described in the instruction manual, which can be found at: http://www.mfm.nmd.ord. Each patient was evaluated six times by the same physical therapist on the day of the patient's medical appointment for 18 months. The first visit preceded the onset of steroid therapy. The interval between the first and second visits and between the second and third visits was three months. The interval between the remaining successive visits was four months. Evaluations were performed before each appointment. The term of consent was signed by the patients/parents and it was previously approved by the Ethics Committee for Analysis of Research Projects of the Department of Neurology, Medical School of the University of São Paulo, São Paulo SP, Brazil). Statistical analysis was performed using ANOVA for repeated measures, followed by Tukey's range test. In each statistical analysis, a significance level of $5 \%(\mathrm{p}<0.05)$ was adopted.

\section{RESULTS}

Forty-four patients with DMD, who were on steroid therapy, were followed. Of these patients, 11 did not complete the study (seven did not regularly attend the assessments, two dropped out of the follow-up study, one did not regularly maintain medication, and one died). Thus, 33 patients completed the study. Of these patients, $22(66.7 \%)$ were ambulant, six $(18.2 \%)$ were non-ambulant, and five (15.1\%) lost walking capacity during the study (Table 1).

D1 was not analyzed in the group of non-ambulant patients, because it measures motor function associated with the standing position and transfer from one place to another. In ambulant patients, D1 and the total score remained stable for 10 to 14 months after starting the treatment (Table 2). There was a marked improvement in D2 motor function in the first six months of treatment, with some time of stability throughout the follow-up period. There was functional gain in D3 during the entire follow-up period (Table 2).

In non-ambulant patients, we observed maintenance of D2 and total score during the follow-up period with functional loss during the last visits for D2, except for D3 measurement, which remained stable throughout the follow-up period (Table 3). In the group of patients who lost walking ability during the follow-up period, D1 began to decline after

Table 2. Comparison of mean percentages of motor functional measure scores on the first evaluation (V0) with each subsequent visit (V1, V2, V3, V4 and V5) in the group of 22 ambulant patients with Duchenne muscular dystrophy.

\begin{tabular}{lcccccc} 
Motor function & $\begin{array}{c}\text { Vo }(\%) \\
\text { baseline }\end{array}$ & $\begin{array}{c}\text { V1 (\%) } \\
\text { 3mo }\end{array}$ & $\begin{array}{c}\text { V2 (\%) } \\
6 \mathrm{mo}\end{array}$ & $\begin{array}{c}\text { V3 (\%) } \\
10 \mathrm{mo}\end{array}$ & $\begin{array}{c}\text { V4 (\%) } \\
14 \mathrm{mo}\end{array}$ & $\begin{array}{c}\text { V5 (\%) } \\
18 \mathrm{mo}\end{array}$ \\
\hline D1 & $69.5 \pm 2.9$ & $71.0 \pm 4.0$ & $69.2 \pm 14.0$ & $65.6 \pm 13.4$ & $61.7 \pm 13.1 * * *$ & $57.7 \pm 12.4 * * *$ \\
D2 & $93 \pm 5.0$ & $94.8 \pm 3.86$ & $95.7 \pm 2.7 * *$ & $94.9 \pm 2.8$ & $93.3 \pm 2.8$ & $91.8 \pm 3.6$ \\
D3 & $84.3 \pm 8.5$ & $87.9 \pm 5.6 *$ & $87.2 \pm 6.2 *$ & $90.0 \pm 5.9 *$ & $90.5 \pm 7 * * *$ & $88.8 \pm 6.6 * *$ \\
Total & $81.6 \pm 7.2$ & $83.5 \pm 7.3$ & $83.2 \pm 6.2$ & $81.8 \pm 6.7$ & $79.7 \pm 6.1$ & $77.3 \pm 6.1 * * *$
\end{tabular}

D1: standing and transfers capacities; D2: axial and proximal motor capacities; D3: distal motor capacity; Total: total score; mo: months; ${ }^{\mathrm{p}<0.05 ; ~} \star \star \mathrm{p}<0.01$; $\star \star \star p<0.001$. 
Table 3. Comparison of mean percentages of motor functional measure scores on the first evaluation (V0) with each subsequent visit (V1, V2, V3, V4 and V5) in the group of six non-ambulant patients with Duchenne muscular dystrophy.

\begin{tabular}{lcccccc} 
Motor function & V0 (\%) & V1 (\%) & V2 (\%) & V3 (\%) & V4 (\%) & V5 (\%) \\
& baseline & 3mo & $6 \mathrm{mo}$ & $10 \mathrm{mo}$ & $4 \mathrm{mo}$ & $18 \mathrm{mo}$ \\
\hline D2 & $50.9 \pm 24.7$ & $55.1 \pm 26.3$ & $52.3 \pm 25.6$ & $54.2 \pm 25.3$ & $46.3 \pm 22.5$ & $41.2 \pm 22.0 * *$ \\
D3 & $71.4 \pm 17.0$ & $74.6 \pm 18.0$ & $74.6 \pm 17.7$ & $71.4 \pm 25.4$ & $67.5 \pm 22.8$ & $64.3 \pm 23.7$ \\
Total & $34.5 \pm 13.2$ & $37.8 \pm 14.6$ & $37.0 \pm 14.6$ & $37.0 \pm 16.49$ & $33.0 \pm 14.0$ & $30.9 \pm 14.9$ \\
\hline
\end{tabular}

D2: axial and proximal motor capacities; D3: distal motor capacity; Total: total score; mo: months; ${ }^{\star} p<0.05 ;{ }^{* *} p<0.01 ;{ }^{* * *} p<0.001$.

Table 4. Comparison of mean percentages of motor functional measure scores on the first evaluation (V0) and with each subsequent visit (V1, V2, V3, V4 and V5) in the group of five patients with Duchenne muscular dystrophy that lost the walk ability.

\begin{tabular}{|c|c|c|c|c|c|c|}
\hline Motor function & $\begin{array}{c}\text { V0 (\%) } \\
\text { baseline }\end{array}$ & $\begin{array}{c}\text { V1 (\%) } \\
3 \text { mo }\end{array}$ & $\begin{array}{l}\text { V2 (\%) } \\
6 \mathrm{mo}\end{array}$ & $\begin{array}{l}\text { V3 (\%) } \\
10 \mathrm{mo}\end{array}$ & $\begin{array}{l}\text { V4 (\%) } \\
14 \mathrm{mo}\end{array}$ & $\begin{array}{l}\text { V5 (\%) } \\
18 \mathrm{mo}\end{array}$ \\
\hline D1 & $33.3 \pm 9.0$ & $31.3 \pm 11.4$ & $22.1 \pm 8.0$ & $15.9 \pm 9.7 * *$ & $12.8 \pm 6.0 * \star *$ & $7.7 \pm 0.0 * \star$ \\
\hline D2 & $91.7 \pm 3.9$ & $92.8 \pm 3.16$ & $92.8 \pm 1.5$ & $91.7 \pm 2.0$ & $88.9 \pm 3.4$ & $83.3 \pm 6.5^{\star \star}$ \\
\hline D3 & $89 . \pm 5.2$ & $90.5 \pm 4.8$ & $93.3 \pm 4.3$ & $92.4 \pm 4.3$ & $89.5 \pm 4.0$ & $85.7 \pm 5.8$ \\
\hline Total & $66.9 \pm 4.2$ & $67.3 \pm 6.3$ & $64.2 \pm 4.0$ & $60.8 \pm 4.2$ & $58.1 \pm 4.1$ & $53.1 \pm 2.8 * * \star$ \\
\hline
\end{tabular}

D1: standing and transfers capacities; D2: axial and proximal motor capacities; D3: distal motor capacity; Total: total score; mo: months; ${ }^{\star} \mathrm{p}<0.05$; ${ }^{\star} \mathrm{p}<0.01$; $\star \star * p<0.001$.

the third visit, D2 and the total score began to decline during the final visits, and D3 remained constant during the followup period (Table 4). With the exception of the two patients who lost their walking ability at the second visit, one patient lost his/her walking ability at the third visit and two patients lost their walking ability at the forth one. The mean scores at the time that walking ability was lost in those patients were: D1 $=22.51 \%$ ( $\pm 4.97 \%), \mathrm{D} 2=92.22 \%( \pm 1.24 \%)$, D3=91.43\% $( \pm 3.99 \%)$, and total score $=63.12 \%( \pm 2.03 \%)$.

\section{DISCUSSION}

Because the MFM displays losses and gains at each stage of the disease and for each motor function, the MFM is an excellent method of evaluating DMD patients on steroid therapy or other new therapeutic strategies. Our aim was to demonstrate the advantages for the use of MFM as a tool for monitoring the functional outcome of patients with DMD on steroid therapy; the purpose was not to evaluate the beneficial effects of medication on disease progression, which have been well recognized during the last two decades ${ }^{2,15-20}$.

In previous studies, several methods have been used to assess and monitor motor function in patients on steroid therapy ${ }^{3,9,11,12}$, and the search for the ideal instrument remains an objective in several centers for neuromuscular diseases ${ }^{9,21}$. The MFM has been applied successfully in some studies of treated DMD patients ${ }^{13,14,22}$. Recently, Vuillerot et al. ${ }^{23}$ compared 12 steroid-treated patients with a Control Group of 12 untreated patients over a 12-month period; patients treated with steroids had more stable total MFM scores and D2 sub-scores, confirming the beneficial use of steroids for patients with DMD. Although muscle strength was not evaluated in our study, a recent report has compared the scores obtained with the Medical Research Council (MRC) index and the MFM ${ }^{23}$.

Since the items assessed by the MFM permit the evaluation of the course of DMD, during the follow-up, our patients were divided into three groups (ambulant patients, non-ambulant patients, and those who lost walking ability during the study period). The division of patients into these groups and the short periods of time between each evaluation allowed a better understanding of the application and the effectiveness of the MFM.

In the group of ambulant patients, the MFM was proven to be effective for mapping disease progression in standing posture and transfer. We noted a period of stability for D1 followed by functional losses at the end of 18 months. Since D1 is related to the ability to walk, our findings were similar to previous results, which demonstrated that medication can extend the walking ability for months to two years ${ }^{2,3,16,18,24}$. Despite the inevitable decline in D1 at the end of the followup period, we found an increase in D2 in the first months of medication, and an increase in D3 throughout the follow-up period. This resulted in the stabilization of the total score. Therefore, the MFM suggests that physical therapeutic activities should focus on proximal, axial, and distal muscles during this period. For DMD is a progressive disease, the maintenance of motor function for months or years can prevent the accumulation of incapacities ${ }^{18}$. Other authors who utilized the MFM found variations in motor functions in the short-term (six months) ${ }^{22}$. However, they suggested that in new studies, patients should be monitored for more than six months, which is the case in the present study.

The dimensions assessed by the MFM seem to indicate with reasonable precision early motor deficits, as well transition periods in the course of the disease. The D1 seems to be the most informative dimension in ambulant patients, 
because it can show percentage values when patients were close to lose their walking ability. In our study, D1 (22.51\%) and the total MFM score $(63.12 \%)$ reflected a cut point moment for the loss of walking ability. However, this conclusion should be reserved, considering the small population of our study. Among the five patients who lost walking ability during the follow-up period in this study, the slowing of disease progression was reflected in D2, D3, and the total MFM score.

Similar findings were also reported by Vuillerot et al. ${ }^{22}$. These authors stressed the possibility of predicting loss of walking ability one year before through the observation of estimated values of $40 \%$ for D1 and $70 \%$ for the total MFM score. Thus, these results could help DMD patients prepare to become wheelchair dependents. In addition, our results with the MFM, especially our estimates of D3 in non-ambulant patients, indicated a benefit of starting steroid therapy even at a later stage of the illness ${ }^{22}$.

The possibility of a longitudinal follow-up study to assess functional independence is a valuable advantage of the MFM, which can be used in all stages of the disease. Other methods of monitoring progression of DMD and the effects of drug interventions focused on ambulatory patients ${ }^{5,8}$ require adjustments and additional assessments $^{9,21}$. Even the Hammersmith scale, broadly utilized, may be less sensitive while the patient becomes less ambulant ${ }^{9}$. Furthermore, the Hammersmith scale requires a different test for evaluating the upper limbs. We also emphasize the advantage of using the MFM for evaluating distal motor function that is not detected using other scales, like the one of Hammersmith, Brooke and Vignos, which are related primarily to gross motor skills. Even the Egen Klassifikation (EK) scale (Egen Klassifikation, translation from Danish) for non-ambulant Duchnenne and Spinal Muscle Atrophy users has no items for evaluation of motor distal function ${ }^{25-27}$.

In conclusion, the MFM scale proved to be applicable to patients with DMD, who are undergoing steroid therapy. The MFM maps the evolution of the disease. It indicates stages of the disease in which motor ability improves, deteriorates, or remains stable, which would be important for planning the rehabilitation treatment. We suggest that additional longitudinal studies should be undertaken but with a larger sample of patients who are in transition to wheelchair dependence.

\section{References}

1. Wagner KR. Approaching a new age in Duchenne muscular dystrophy treatment. Neurotherapeutics 2008;5:583-591.

2. Fenichel GM, Florence JM, Pestronk A, et al. Long-term benefit from prednisone therapy in Duchenne muscular dystrophy. Neurology 1991;41:1874-1877.

3. Balaban B, Matthews DJ, Clayton GH, Carry T. Corticosteroid treatment and functional improvement in Duchenne muscular dystrophy: long term effect. Am J Phys Med Reabil 2005;84:843-850.

4. Bushby K, Finkel R, Birnkrant D, et al. Diagnosis and management of Duchenne muscular dystrophy, part 1: diagnosis, and pharmacological and psychosocial management. Lancet Neurol 2010;9:77-93.

5. Allsop KG, Ziter FA. Loss of strengh and functional decline in Duchenne's dystrophy. Arch Neurol 1981;38:406-411.

6. Scott OM, Hyde AS, Goddard C, Dubowitz V. Quantification of muscle function in children: a prospective study in Duchenne muscular dystrophy. Muscle Nerve 1982;5:291-301.

7. Brooke $\mathrm{MH}$, Fenichel GM, Griggs RC, et al. Clinical investigation I Duchenne dystrophy: 2. determination of the "power" of therapeutics trials based on the natural history. Muscle Nerve 1983;6:91-103.

8. Scott E, Mawson SJ. Measurement in Duchenne muscular dystrophy: considerations in the development of a neuromuscular assesment tool. Dev Med Child Neurol 2006;48:540-544.

9. Bushby K, Muntoni F, Urtizberea A, Hughes R, Griggs R. Report on the 124th ENMC international workshop treatment of Duchenne muscular dystrophy; defining the gold standards of management in the use of corticosteroids 2-4 April 2004, Naarden, The Netherlands. Neuromuscul Disord 2004;14:526-534.

10. Mercuri E, Mayhew A, Muntoni F, et al. Towards harmonisation of outcome measures for DMD and SMA within TREAT-NMD; report of three expert workshops: TREAT-NMD/ENMC workshop on outcome measures, $12^{\text {th }}-13^{\text {th }}$ May 2007, Naarden, The N Netherlands; TREATNMD workshop on outcome measures in experimental trials for DMD, 30th June-1 $1^{\text {st }}$ July 2007, Naarden, The Netherlands; conjoint institute of myology TREAT-NMD meeting on physical activity monitoring in neuromuscular disorders, 11 th July 2007, Paris, France. Neuromuscul Disord 2008;18:894-903.

11. Parreira SL, Resende MB, Peduto MDC, Marie SKN, Carvalho MS, Reed UC. Quantification of muscle strength and motor ability in patients with Duchenne muscular dystrophy on steroid therapy. Arq Neuropsiquiatr 2007;65:245-250.

12. Parreira SL, Resende MB, Zanoteli E, Carvalho MS, Marie SK, Reed UC. Comparison of motor strength and function in patients with Duchenne muscular dystrophy with or without steroid therapy. Arq Neuropsiquiatr 2010;68:683-688.

13. Bèrard C, Payan C, Hodgkinson I, Fermanian J, The MFM Collaborative Study Group. A motor functional measure scale for neuromuscular disease. Construction and validation study. Neuromuscul Disord 2005;15:463-470.

14. Iwabe C, Miranda-Pfeilsticker BH, Nucci AM. Medida da função motora: versão da escala para o português e estudo de confiabilidade. Rev Bras Fisioter São Carlos 2008;12:417-424.

15. Connolly A, Schierbecker J, Renna R, Florence J. High dose weekly oral prednisone improves strength in boys with Duchenne muscular dystrophy. Neuromuscul Disord 2002;12:917-925.

16. Manzur AY, Kinali M, Muntoni F. Update on the management of Duchenne muscular dystrophy. Arch Dis Child 2008;93:986-990.

17. Houde S, Filiatrault M, Fournier A, et al. Deflazacort use in Duchenne muscular dystrophy: an 8-year follow-up. Pediatr Neurol 2008;38:200-206.

18. Biggar WD, Harris VA, Eliasoph L, Alman B. Long- term benefits of deflazacort treatment for boys with Duchenne muscular dystrophy in their second decade. Neuromuscul Disord 2006;16:249-255.

19. Moxley RT 3rd, Pandya S, Ciafaloni E, Fox DJ, Campbell K. Change in natural history of Duchenne muscular dystrophy with long term corticosteroid treatment implications for management. J Child Neurol 2010;25:1116-1129.

20. Bushby K, Griggs R, on behalf of the MSG/ENMC for DMD Trial study group. $145^{\text {th }}$ ENMC International Workshop: planning for an 
international trial of steroid dosage regimes in DMD (FOR DMD) 22$24^{\text {th }}$ October 2006, Naarden, The Netherlands. Neuromuscul Disord 2007;17:423-428.

21. Nair KPS, Vasanth A, Gourie DM, et al. Disabilities in children with Duchenne muscular dystrophy: a profile. J Rehabil Med 2001;33: 147-149.

22. Vuillerot C, Girardot F, Payan C, et al. Monitoring changes and predicting loss of ambulation in Duchenne muscular dystrophy with the motor function measure. Dev Med Child Neurol 2010;52:60-65.

23. Benaïn C, Sacconi S, Fournier-Mehouas M, Tanant V, Desnuelle C. Analyse de validité de la mesure de la function motrice (MFM) en pratique de consultation adulte d'un centre de référenc pour maladies neuromusculaires. Revue Neurol (Paris) 2010;166:49-53.
24. Mc Donald CM, Abresh RT, Carter GT, et al. Profiles of neuromuscular diseases. Am J Phys Med Rehabilit 1995;74:70-92.

25. Steffensen B, Hyde S, Lyager S, Mattsson E. Validity of the EK scale: a functional assessment of non- ambulatory individuals with Duchenne muscular dystrophy or spinal muscular atrophy. Physiother Resp Inte 2001;6:119-134.

26. Martinez JAB, Brunherotti MA, Assis MR, Sobreira CFR. Validação da escala motora funcional EK para a língua portuguesa. Rev Assoc Med Bras 2006;52:347-351.

27. Bèrard C, Payan C, Fermanian J, Girardot F, Groupe d'Etude MFM. La mesure de fonction motrice, outil d'évaluation clinique des maladies neuromusculaires. Etude de validation. Rev Neurol (Paris) 2006;162:485-493. 